\title{
Equilibrium Anionic Polymerization of Hexanal
}

\author{
Kazuhiko Hashimoto and Hiroshi Sumitomo \\ Faculty of Agriculture, Nagoya University, \\ Chikusa-ku, Nagoya 464, Japan.
}

(Received May 29, 1979)

\begin{abstract}
KEY WORDS Equilibrium Anionic Polymerization / Hexanal / Aliphatic Aldehydes / Thermodynamic Parameter / Substituent Effect /
\end{abstract}

Early investigations on the polymerization of aldehydes have been comprehensively summarized in several articles. ${ }^{1-4}$ Most of the pioneering thermodynamic studies were related to the equilibrium polymerization of formaldehyde and haloaldehydes under different experimental conditions. ${ }^{5-20}$ For more quantitative understanding of their polymerizability, the thermodynamic parameters determined under the same conditions should be compared, because these are known to depend upon phase states in monomer and polymer, initial monomer concentration, kind of solvent, temperature range, and so on. ${ }^{21}$ On the other hand, the improvements of high vacuum technique and the ingenious choice of the polymerization conditions have enabled the equilibrium anionic polymerization of aliphatic aldehydes containing $\alpha$-hydrogens to be performed without simultaneous side reactions such as aldol condensation. ${ }^{14,22-27}$ In the present study the equilibrium anionic polymerization of hexanal $\left(\mathrm{O}=\mathrm{CHCH}_{2} \mathrm{CH}_{2} \mathrm{CH}_{2} \mathrm{CH}_{2} \mathrm{CH}_{3}, \mathrm{HA}\right)$ has been achieved and compared with those of other aliphatic aldehydes ${ }^{25.27}$ in order to estimate the effects of $n$ alkyl groups on the polymerization of aldehydes.

\section{EXPERIMENTAL}

All procedures, including purification of materials, preparation of initiator, and polymerization, were carried out in a high-vacuum system. ${ }^{24.28}$

\section{Materials}

Commercially available hexanal (HA) was purified by rectification in an atmosphere of dry nitrogen through a packed column placed in an adiabatic vacuum glass cylinder (the number of the theoretical plates, $c a$. 60). The main fraction was distilled again in vacuo after drying over molecular sieves. Tetrahydrofuran(THF) and acetic anhydride were purified by the same methods as described in a previous paper. ${ }^{24}$ The benzophenone-monolithium complex $(\mathrm{Li}-\mathrm{BzPh})$ solution in THF was prepared by mixing an equimolar amount of benzophenone with the benzophenone-dilithium complex-THF solution, which was previously produced quantitatively by the addition of benzophenone-THF solution to an excess of lithium metal at $0^{\circ} \mathrm{C} .{ }^{24.28}$

\section{Polymerization}

A THF solution of HA $\left(2 \mathrm{~mol} \mathrm{1}^{-1}\right)$ was prepared and subdivided into $5 \mathrm{ml}$ portions in a high vacuum. The initiator solution $\left(0.05 \mathrm{~mol}^{-1}\right)$ containing $c a$. $0.12 \mathrm{mmol}$ of $\mathrm{Li}-\mathrm{BzPh}$ complex was diluted with the required amount of THF, which was calculated so as to give the desired initial concentrations of the initiator and the monomer at the applied polymerization temperature. In order to avoid possible side reactions such as aldol condensation, especially during the initiation step, ${ }^{22-24}$ the THF solution of $\mathrm{HA}$ was poured into $\mathrm{Li}-\mathrm{BzPh}$ solution under vigorous stirring at a temperature below $-78^{\circ} \mathrm{C}$. After the solution was kept at a constant temperature for a desired time, a large amount of acetic anhydride (3$4 \mathrm{ml}$ ) was added to the solution in order to terminate the reaction at the polymerization temperature; then the solution was allowed to stand for more than $3 \mathrm{~h}$.

\section{Determination of Residual Monomer Concentration}

All volatile components were collected by vacuum distillation from the polymerization mixture, and 
$150-200 \mathrm{mg}$ of anthracene used as an internal reference was diluted into them. The NMR spectrum of the mixture was measured with a Japan Electronics Model JNM-MH-100 high-resolution spectrometer operating at $100 \mathrm{MHz}$ at room temperature, tetramethylsilane being used as an internal standard. The sharp peaks were expanded by a decrease of the sweep width. The residual monomer concentration was determined from the ratio of the peak at $\delta 9.6 \mathrm{ppm}$ assigned to the methine proton of HA monomer to the peak at $8.45 \mathrm{ppm}$ assigned to the methine protons of anthracene.

\section{RESULTS AND DISCUSSION}

Hexanal(HA) was polymerized in THF at an initial monomer concentration of $0.61-0.92 \mathrm{~mol}$ $1^{-1}$ at various temperatures from $-92^{\circ} \mathrm{C}$ to $-71^{\circ} \mathrm{C}$ by using $\mathrm{Li}-\mathrm{BzPh}$ complex as an initiator. Simultaneously most of the resulting poly(hexanal) precipitated because of its low solubility in THF at low temperature, but no residual. HA monomer deposited. The polymer precipitated as a fine white solid rather than as a viscous phase and it absorbed little residual monomer on its surface. When the initial monomer concentration was higher, the polymerization proceeded with the simultaneous deposition of the resulting polymer as a viscous layer, which may contain a part of the residual monomer. Therefore, the polymerization reaction in the present system can be practically regarded as a simple conversion of HA monomer in THF to the solid polymer so far as the polymerization was carried out at the above-mentioned initial monomer concentrations and temperatures.

The values of the residual monomer concentration $[\mathrm{M}]_{\mathrm{r}}$ at $-71^{\circ} \mathrm{C}$ and $-78^{\circ} \mathrm{C}$ determined by the NMR spectroscopy became constant at least after $9 \mathrm{~h}$. The existence of an equilibrium state between the resulting polymer and the residual monomer in the present system was confirmed by the following two-step polymerization (Table I). After the first polymerization at $-71^{\circ} \mathrm{C}$, the polymerization temperature was lowered to $-78^{\circ} \mathrm{C}$, which allowed further polymerization until the value of $[\mathrm{M}]_{\mathrm{r}}$ was consistent with that in the direct polymerization at $-78^{\circ} \mathrm{C}$.

Table I. Two-step polymerization of hexanal ${ }^{\mathbf{a}}$

\begin{tabular}{|c|c|c|c|c|c|c|c|}
\hline \multirow{3}{*}{$\begin{array}{c}\text { Expt. } \\
\text { No. }\end{array}$} & \multirow{3}{*}{$\frac{[\mathrm{M}]_{0}}{\mathrm{moll}^{-1}}$} & \multirow{3}{*}{$\frac{[\mathrm{I}]_{0} \times 10^{3}}{\mathrm{moll}^{-1}}$} & \multicolumn{2}{|c|}{ First step } & \multicolumn{2}{|c|}{ Second step } & \multirow{3}{*}{$\frac{[\mathrm{M}]_{\mathrm{r}}}{\mathrm{moll}^{-1}}$} \\
\hline & & & \multirow{2}{*}{$\frac{\text { Temp }}{{ }^{\circ} \mathrm{C}}$} & \multirow{2}{*}{$\frac{\text { Time }}{h}$} & \multirow{2}{*}{$\frac{\text { Temp }}{{ }^{\circ} \mathrm{C}}$} & \multirow{2}{*}{$\frac{\text { Time }}{h}$} & \\
\hline & & & & & & & \\
\hline 7 & 0.844 & 10.7 & -71 & 12 & - & - & 0.687 \\
\hline 12 & 0.841 & 11.8 & -71 & 12 & -78 & 96 & 0.462 \\
\hline 11 & 0.793 & 9.9 & -78 & 24 & - & - & 0.456 \\
\hline
\end{tabular}

${ }^{\text {a }}$ Initiator, $\mathrm{Li}-\mathrm{Bz} \mathrm{Ph}$; solvent, tetrahydrofuran.

Table II. Equilibrium anionic polymerization of hexanal ${ }^{\mathrm{a}}$

\begin{tabular}{|c|c|c|c|c|c|c|}
\hline \multirow{2}{*}{$\begin{array}{c}\text { Expt. } \\
\text { No. }\end{array}$} & {$[\mathrm{M}]_{0}$} & \multirow{2}{*}{$\frac{[\mathrm{I}]_{0} \times 10^{3}}{\mathrm{moll}^{-1}}$} & \multirow{2}{*}{$\frac{[\mathrm{M}]_{0}}{[\mathrm{I}]_{0}}$} & \multirow{2}{*}{$\frac{\text { Temp }}{{ }^{\circ} \mathrm{C}}$} & \multirow{2}{*}{$\frac{\text { Time }}{\mathrm{h}}$} & \multirow{2}{*}{$\frac{[\mathrm{M}]_{\mathrm{e}}}{\mathrm{moll}^{-1}}$} \\
\hline & $\mathrm{moll}^{-1}$ & & & & & \\
\hline 7 & 0.844 & 10.7 & 78.8 & -71 & 12 & 0.687 \\
\hline 8 & 0.860 & 10.5 & 81.4 & -71 & 24 & 0.686 \\
\hline 17 & 0.919 & 10.9 & 84.2 & -78 & 9 & 0.456 \\
\hline 11 & 0.793 & 9.9 & 80.2 & -78 & 24 & 0.456 \\
\hline 10 & 0.785 & 9.9 & 79.4 & -78 & 48 & 0.469 \\
\hline 15 & 0.684 & 8.0 & 86.0 & -84 & 48 & 0.337 \\
\hline 16 & 0.666 & 8.0 & 82.8 & -84 & 72 & 0.321 \\
\hline 13 & 0.611 & 7.2 & 84.9 & -92 & 72 & 0.204 \\
\hline 14 & 0.611 & 7.2 & 84.9 & -92 & 120 & 0.200 \\
\hline
\end{tabular}

a Initiator, $\mathrm{Li}-\mathrm{Bz} \mathrm{Ph}$; solvent, tetrahydrofuran. 
The values of equilibrium monomer concentration $[\mathrm{M}]_{\mathrm{e}}$ in the polymerization of $\mathrm{HA}$ in THF at a temperature range of $-92^{\circ} \mathrm{C}$ to $-71^{\circ} \mathrm{C}$ are summarized in Table II. From the plot of $\ln [\mathrm{M}]_{\mathrm{e}}$ vs. 1/T in Figure $1, \Delta H_{\mathrm{sc}}$ and $\Delta S_{\mathrm{sc}}$ for the polymerization of $\mathrm{HA}$ in THF were evaluated to be $-4.2 \pm 0.2 \mathrm{kcal} \mathrm{mol}^{-1}\left(-17.6 \pm 0.8 \mathrm{~kJ} \mathrm{~mol}^{-1}\right)$ and $-20.1 \pm 1.0 \mathrm{cal} \mathrm{mol}^{-1} \mathrm{deg}^{-1} \quad\left(-83.9 \pm 4.3 \mathrm{~J} \mathrm{~mol}^{-1}\right.$ $\left.\operatorname{deg}^{-1}\right)$, respectively.

$$
\begin{aligned}
\Delta G_{\mathrm{sc}} / R T & =\left(\Delta H_{\mathrm{sc}} / R T\right)-\left(\Delta S_{\mathrm{sc}} / R\right) \\
& =-\ln K=\ln [\mathrm{M}]_{\mathrm{e}}
\end{aligned}
$$

where $\Delta G_{\mathrm{sc}}, \Delta H_{\mathrm{sc}}$, and $\Delta S_{\mathrm{sc}}$, are the changes in the free energy, standard enthalpy, and entropy, respectively, corresponding to the conversion of one mole of monomer in solution to one base-mole of condensed polymer (subscripts $\mathrm{s}$ and $\mathrm{c}$ refer to the solution and condensed states, respectively). The ceiling temperature at which $[\mathrm{M}]_{\mathrm{e}}$ is $1 \mathrm{~mol}^{-1}$ was $-63^{\circ} \mathrm{C}$.

The thermodynamic parameters for the polymerization of various aldehydes in THF are summarized in Table III. While the influences of $\alpha$ - and $\beta$-polar substituents on the polymerizability of aliphatic aldehydes are estimated from the comparison of the data for the polymerization of some chloro- or methyl-substituted aldehydes and polar-substituted aldehydes, respectively, ${ }^{13,14,24-26}$ the effects of the long alkyl groups are speculated on from the comparison of the values of $\Delta H_{\mathrm{sc}}$ and $\Delta S_{\mathrm{sc}}$ for the higher aliphatic aldehydes. The absolute values distinctly diminished with the increase of the length of $n$-alkyl

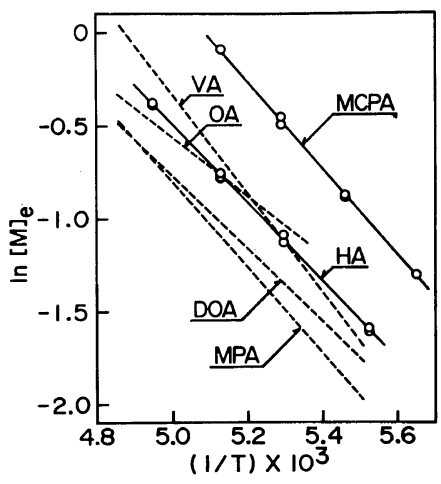

Figure 1. Temperature dependence of equilibrium monomer concentration in anionic polymerization of various aldehydes in tetrahydrofuran.

groups, and their gradients also seem to decrease with its increase. The former tendency has been seen in their equilibrium cyclotrimerization, too. ${ }^{29,30}$ The decrease of the absolute value of $\Delta S_{\mathrm{sc}}$ in the case of higher aldehydes means that the mobility of the long alkyl groups must increase the entropy more effectively in the polymer states rather than in the monomer states. On the other hand, the enthalpy in monomer states may be decreased by the weak aggregation of polar aldehyde groups due to their intermolecular dipole-dipole interactions, which are enhanced by the neighboring nonpolar hydrophobic long alkyl groups. Based on the ceiling temperature, the long alkyl groups are considered to increase their thermodynamic polymerizability.

\begin{tabular}{|c|c|c|c|c|}
\hline \multirow{2}{*}{ Monomer } & $-\Delta H_{\mathrm{ss}}$ & $-\Delta S_{\mathrm{ss}}$ & $T_{\mathrm{c}_{\mathrm{ss}}}$ & \multirow{2}{*}{ Reference } \\
\hline & $\mathrm{kcal} \mathrm{mol}^{-1 \mathrm{~d}}$ & cal $\mathrm{mol}^{-1} \mathrm{deg}^{-1 \mathrm{~d}}$ & ${ }^{\circ} \mathrm{C}$ & \\
\hline $\mathrm{VA}, \mathrm{O}=\mathrm{CHCH}_{2} \mathrm{CH}_{2} \mathrm{CH}_{2} \mathrm{CH}_{3}$ & $5.3^{\mathrm{a}}$ & $25.7^{\mathrm{b}}$ & $-68^{c}$ & 27 \\
\hline $\mathrm{HA}, \mathrm{O}=\mathrm{CHCH}_{2} \mathrm{CH}_{2} \mathrm{CH}_{2} \mathrm{CH}_{2} \mathrm{CH}_{3}$ & $4.2^{\mathrm{a}}$ & $20.1^{\mathrm{b}}$ & $-63^{\mathrm{c}}$ & This work \\
\hline $\mathrm{OA}, \mathrm{O}=\mathrm{CHCH}_{2} \mathrm{CH}_{2} \mathrm{CH}_{2} \mathrm{CH}_{2} \mathrm{CH}_{2} \mathrm{CH}_{2} \mathrm{CH}_{3}$ & $3.4^{\mathrm{a}}$ & $15.7^{\mathrm{b}}$ & $-59^{c}$ & 25 \\
\hline $\mathrm{MPA}, \mathrm{O}=\mathrm{CHCH}_{2} \mathrm{CH}_{2} \mathrm{OCH}_{3}$ & 4.8 & 22.4 & -59 & 24 \\
\hline $\mathrm{DOA}, \mathrm{O}=\mathrm{CHCH}_{2} \mathrm{CH}_{2} \mathrm{OCH}_{2} \mathrm{CH}_{2} \mathrm{OCH}_{3}$ & 4.0 & 18.4 & -56 & 25 \\
\hline $\mathrm{MCPA}, \mathrm{O}=\mathrm{CHCH}_{2} \mathrm{CH}_{2} \mathrm{COOCH}_{3}$ & 4.3 & 21.9 & -76 & 26 \\
\hline----------- & --- & ----- & -- & --- \\
\hline $\mathrm{O}=\mathrm{CHCCl}_{3}$ & 3.5 & 12.4 & 11 & 13 \\
\hline $\mathrm{O}=\mathrm{CHCCl}_{2} \mathrm{CH}_{3}$ & 4.1 & 16.5 & -24 & 14 \\
\hline $\mathrm{O}=\mathrm{CHCCl}\left(\mathrm{CH}_{3}\right)_{2}$ & 4.7 & 21.6 & -54 & 14 \\
\hline $\mathrm{O}=\mathrm{CHCH}\left(\mathrm{CH}_{3}\right)_{2}$ & 3.7 & 17.6 & -63 & 14 \\
\hline $\mathrm{O}=\mathrm{CHC}\left(\mathrm{CH}_{3}\right)_{3}$ & - & - & $<-78$ & 14 \\
\hline
\end{tabular}

Table III. Thermodynamic parameters for the polymerization of aldehydes in tetrahydrofuran

${ }^{\mathrm{a}}-\Delta H_{\mathrm{sc} \cdot} \cdot{ }^{\mathrm{b}}-\Delta S_{\mathrm{sc} \cdot}{ }^{\mathrm{c}} T_{\mathrm{c}_{\mathrm{sc}}} \cdot{ }^{\mathrm{d}} 1 \mathrm{cal}=4.184 \mathrm{~J}$. 


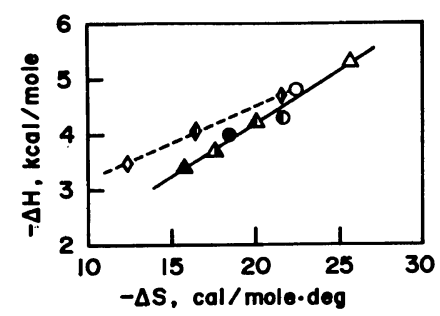

Figure 2. Relationship between $-\Delta H$ and $-\Delta S$ for equilibrium polymerization of aldehydes $(\mathrm{O}=\mathrm{CHR})$ in tetrahydrofuran:

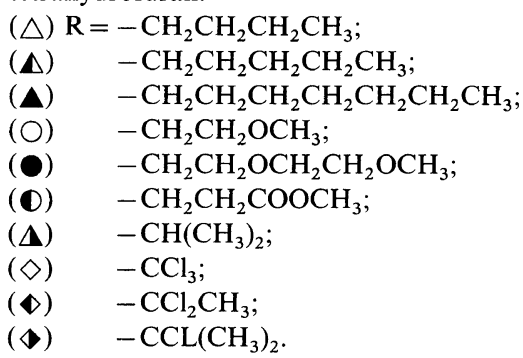

The compensation relation between $-\Delta H$ and $-\Delta S$ for the equilibrium polymerization of aldehydes in THF is shown in Figure 2. There seems to be a linear relationship of the data for the higher aliphatic aldehydes as well as for the chloro- or methyl-substituted aldehydes. The isoequilibrium temperature for the former compounds is estimated to be $-80^{\circ} \mathrm{C}$, which is higher than that for the latters $\left(-140^{\circ} \mathrm{C}\right) .^{14}$ The data for the polar-substituted aldehydes lie near but not upon the straight line formed by the data for the aliphatic aldehydes. Such a linear relationship is found only among the data for the homologous aldehydes, for examples, higher aliphatic aldehydes and chloro- or methylsubstituted aldehydes.

Acknowledgment. The authors are grateful to $\mathrm{Mr}$. Osakabe for his help in a part of the experimental work.

\section{REFERENCES}

1. J. Furukawa and T. Saegusa, "Polymerization of Aldehydes and Oxides", Wiley-Interscience, New York, N. Y., 1963.
2. O. Vogl, "Polyaldehydes", Dekker, New York, N. Y., 1967.

3. O. Vogl, J. Macromol.Sci., Revs. Macromol. Chem., C12, 109 (1975).

4. O. Vogl, J. Macromol. Sci.-Chem., A9, 663 (1975).

5. F. S. Daiton, K. J. Ivin, and D. A. G. Walmsley. Trans. Faraday Soc., 55, 61 (1959).

6. Y. Iwasa and T. Imoto, Nippon Kagaku Zasshi, 84, 29 (1963).

7. W. K. Busfield and E. Whalley, Trans. Faraday Soc., 59, 679 (1963).

8. A. M. North and D. Richardson, Polymer, 6, 333 (1965).

9. W. K. Busfield, Polymer, 7, 541 (1966).

10. T. P. Melia, Polymer, 7, 640 (1966).

11. O. Vogl, J. Macromol. Sci.-Chem., A1, 243 (1967).

12. C. Aso, S. Tagami, and T. Kunitake, J. Polym. Sci., A-1, 7, 497 (1969).

13. I. Mita, I. Imai, and H. Kambe, Makromol. Chem., 137, 143 (1970).

14. I. Mita, I. Imai, and H. Kambe, Makromol. Chem., 137, 155 (1970).

15. I. Mita, I. Imai, and H. Kambe, Makromol. Chem., 137, 169 (1970).

16. W. K. Busfield and D. Merigold, Makromol. Chem., 138, 65 (1970)

17. W. M. D. Bryant and J. B. Thompson, J. Polym. Sci., $A-1$, 9, 2523 (1971).

18. W. K. Busfield and I. J. McEwen, Eur. Polym. J., 9, 1143 (1973).

19. M. Okamoto and J. Osugi, Nippon Kagaku Kaishi, 31 (1974).

20. M. Okamoto and J. Osugi, Nippon Kagaku Kaishi, 928 (1975).

21. H. Sawada, "Thermodynamics of Polymerization", Dekker, New York, N. Y., 1976.

22. K. Hashimoto and H. Sumitomo, J. Polym. Sci., A-1, 7, 1549 (1969)

23. I. Mita, S. Yabe, I. Imai, and H. Kambe, Makromol. Chem., 137, 133 (1970).

24. K. Hashimoto, H. Sumitomo, and S. Ohsawa, $J$. Polym. Sci., Polym. Chem. Ed., 13, 2775 (1975).

25. K. Hashimoto and H. Sumitomo, and S. Ohsawa, $J$. Polym. Sci., Polym. Chem. Ed., 16, 435 (1978).

26. K. Hashimoto and H. Sumitomo, J. Polym. Sci., Polym. Chem. Ed., in press.

27. K. Hashimoto, H. Sumitomo, and S. Ohsawa, $J$. Polym. Sci., Polym. Chem. Ed., 14, 1221 (1976).

28. H. Sumitomo and K. Hashimoto, J. Polym. Sci. A-1, 7, 1331 (1969)

29. K. Hashimoto, H. Sumitomo, and S. Kawase, J. Polym. Sci., Polym. Chem. Ed., 15, 1609 (1977).

30. K. Hashimoto, H. Sumitomo, and S. Kawase, J. Polym. Sci., Polym. Chem. Ed., 16, 2327 (1978). 